\title{
78. Role of the Pituitary Gland in Melanization in the Skin of the Goldfish, Carassius auratus, Induced by X-ray Irradiation
}

\author{
By Nobuo Egami, ${ }^{*}$ Hisami EтoH, ${ }^{*)}$ Chikashi Tachi,*) \\ Kazuko AoKI,*) and Ryoichi ARAI**) \\ (Comm. by Yô K. OKadA, M.J.A., July 12, 1962)
}

It has been shown by Chavin (1956) that the immersion of xanthic goldfish in a salt solution causes the appearance of epidermal melanophores but similar treatment does not elicit the response in hypophysectomized goldfish. Furthermore, he has reported that among various pituitary hormones, only the adrenocorticotropic hormone $(\mathrm{ACTH})$ has the potency to initiate melanin synthesis in the skin of hypophysectomized goldfish. From these results, he has concluded that the release of ACTH from the pituitary is stimulated by exposing the fish to a salt solution (Chavin, 1959).

On the other hand, it has been pointed out by several authors that melanophores appear in the skin of xanthic goldfish following irradiation by X-rays (Smith, 1932; Ellinger, 1940; Shechmeister et al., 1962).

As a part of the investigation intended to clarify how the pattern of hormone secretion from the pituitary gland is modified by exposing the animals to ionizing radiation, role of the pituitary gland in the melanogenesis caused by $\mathrm{X}$-ray irradiation in the goldfish, Carassius auratus, was studied. The results of the preliminary experiments will be briefly described in this report.

In all series of experiments, a single dose of $\mathrm{X}$-rays was given to each fish. The conditions of irradiation were as follows: 200 kvp., $20 \mathrm{ma}, 0.5 \mathrm{~mm} \mathrm{Cu}$ and $0.5 \mathrm{~mm} \mathrm{Al} \mathrm{filters,} \mathrm{target-object} \mathrm{distance}$ about $25 \mathrm{~cm}$, dose rate $400 \mathrm{r} / \mathrm{min}$.

In the first series, six groups of six goldfish were irradiated with $250,500,1000,2000,4000$, and $8000 \mathrm{r}$ of X-rays, respectively. In all fish given 4000 and $8000 \mathrm{r}$ and most of those receiving 500-2000 r, melanogenic effects of $\mathrm{X}$-rays were manifested in the fins and the skin within 10 days after the irradiation. No melanogenesis took place in fish receiving $250 \mathrm{r}$ as well as the non-irradiated controls. Generally speaking, the melanization was increased in degree with the doses applied.

\footnotetext{
*) Division of Biology, National Institute of Radiological Sciences, Chiba.

**) Zoological Institute, Faculty of Science, University of Tokyo, Tokyo.
} 
In the second series, the anterior or posterior half of the body was shielded from X-rays with $4 \mathrm{~mm}$ lead sheet. Following irradiation, it was found that melanophores appeared in both the shielded and exposed parts of the skin. Therefore, it seems evident that the initiation of melanin formation was not direct local effect of X-rays to the tissue. Moreover, as will be seen from Figure 1, the irradiation of the anterior half of the body caused the melanization as readily as the whole body irradiation, while the irradiation of the

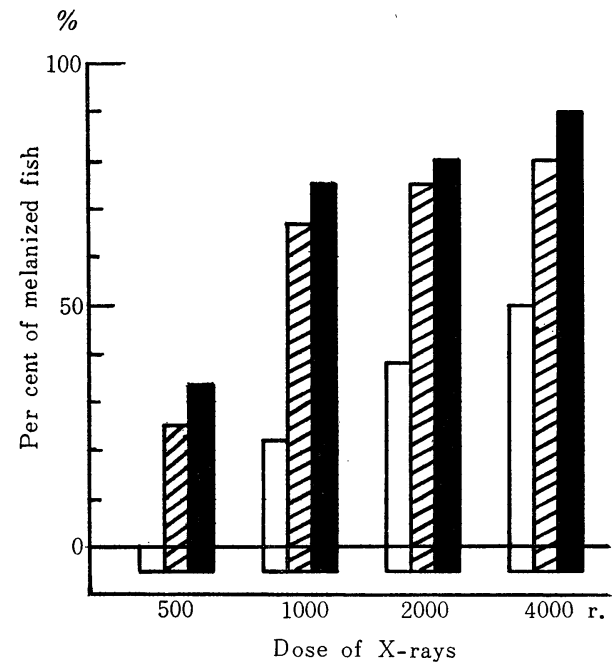

Figure. Effect of X-ray irradiation on melanization in goldfish. Solid bars; per cent of melanized fish produced by whole body irradiation, shaded bars; that following irradiation of anterior half, empty bars; that following irradiation of posterior half.

posterior half was much less effective in causing the melanization than that of the anterior half, at least in the cases when the doses were small. The results suggest that in the mechanism involved in the X-ray melanization, the anterior half of the body was more important than the posterior half.

In the third series, three groups of four hypophysectomized goldfish were exposed to 1000,2000 , and $4000 \mathrm{r}$ of X-rays, respectively. Mortality of the fish exposed to $4000 \mathrm{r}$ was high, but three fish receiving $2000 \mathrm{r}$ and four given $1000 \mathrm{r}$ survived for 9 days or more after the irradiation. In all these completely hypophysectomized fish, no melanogenetic effects were obtained. Therefore, it appears evident that the pituitary gland plays an essential role in the melanization following X-ray irradiation.

The fourth series of experiments was carried out with two groups (Groups A and B) of five hypophysectomized goldfish. In Group A, pituitary glands taken out from five non-irradiated gold- 
fish were implanted intraperitoneally to each fish, and in Group B each fish was implanted with five pituitary glands from the fish irradiated with $2000 \mathrm{r}$ of X-rays 5 or 4 days before. Three fish of Group A and two of Group B died within 3 days after the implantation. On the 9th day after the first implantation, two fish of both groups showed an indication of melanin formation in their fins. No marked difference was found in the degree of the melanization between the two groups. Therefore, it is likely that the implanted pituitary glands from both intact and irradiated donors were similarly active in producing melanophores. It may be that the secretion of hormone related to melanogenesis by the pituitary gland is stimulated by $\mathrm{X}$-rays but storage of the hormone in the pituitary is not increased.

In the fifth series, daily intraperitoneal injections of $1 \mathrm{I}$. U. of an ACTH preparation (Daiichi Seiyaku Co., Tokyo) were given for 4 successive days to five hypophysectomized and five intact fish. Melanogenesis took place in four hypophysectomized and five intact fish within 8 days after the commencement of the injection, but the development of melanophores was less marked in the hypophsectomized fish than in the intact fish. The result suggests that ACTH has the melanogenesis stimulating activity.

From these results, it is highly probable that ACTH secretion from pituitary gland is stimulated by exposing the goldfish to $\mathrm{X}$ rays, and the melanophores in the skin are produced by the oversecretion of the hormone.

Experiments on a larger scale are now in progress and the results will be published in detail elsewhere in future.

We are indebted to Dr. Yô K. Okada of National Museum of Natural Science, Prof. K. Takewaki of Tokyo University, and to Dr. Y. Nakao of National Institute of Radiological Sciences for their kind encouragement during the course of the present experiment.

\section{References}

1) Chavin, W.: J. Exp. Zool., 133, 1 (1956).

2) Chavin, W.: Pigment Cell Biology, New York, 63 (1959).

3) Ellinger, F.: Proc. Soc. Exp. Biol. and Med., 45, 148 (1940).

4) Shechmeister, I. L., L. J. Watson, V. W. Cole, and L. L. Jackson: Radiation Res., 16, 89 (1962).

5) Smith, G. M.: Amer. J. Cancer, 16, 863 (1932). 